\title{
Cost and Efficiency Analysis of PV Transformer-Less Inverter Topology to Grid Connection
}

\author{
Shahreen Noor, Noman H. Khan and K.M. A. Al Woadud
}

\begin{abstract}
Photovoltaic (PV) inverters bear a part and parcel role due to cost and power efficiency where it can be used either in Transformer based system or Transformer-less system. Both system even though the renewable energy which is fully Environmental friendly, however some limitations such as bulky system, maintenance cost increasing indicate for avoiding the Transformer based inverter. In contrast, Transformer -less inverter topology is recovering the TRX based issue and to reduce the overall system cost size with high efficiency. In this paper, Transformer -based inverters have been discussed as well as Transformer -less (TRX) inverter topologies and main focusing part is the cost analysis of TRX inverter topology to grid connection and the different marking process of PV-TRX Inverter Topology to Grid Connection has been shown as well as comparison will be shown with Bangladesh.
\end{abstract}

Index Terms - Solar Panel; TRX Inverter; Demand; Costing effect; Marketing Process.

\section{INTRODUCTION}

The solar cell gets energy from the sunlight, which is cost free and fully pure. Hence, it can be taken as much as energy from the solar cells that actually have been getting through the ray of light. On the other hand, inside of the solar cell has photon that has $\mathrm{p}$ and $\mathrm{n}$ channel where it can possible to get electricity. After that, it can be controlled and transferred to battery as loaded [1]-[3]. The PV cells are integrated to form solar panels, which could also be used for producing hot water as well. A series connection of PV cells in a solar panel gives voltage in the range of 10 to $30 \mathrm{~V}$ with $50 \mathrm{~W}$ power rating with current of several amperes [4]-[6]. A further series connection of such modules in series can lead to generating as high a voltage as $150 \mathrm{~V}$. However, the main limitation in solar power generation is low power efficiency which partly is due to the use of many power electronic devices in series. The PV panels are used stand alone or even connected to grid; in both of the cases, power conditioning and regulation are the core components [7][11]. In the case of grid tied solar generation, inverters become the second core components to be used; inverter may be TRX-based or TRX. However, in both cases, it does

Published on March 16, 2017.

S. Noor is a Lecturer in the Department of Electrical and Electronic Engineering (EEE), Uttara University (UU), Dhaka-1230, Bangladesh. (email: labonnoshahreen@gmail.com).

Md. N. H. Khan is a Lecturer in the Department of Electrical and Electronic Engineering (EEE), Uttara University (UU), Dhaka-1230, Bangladesh. (e-mail: nomanxp76.eee@uttaraUniversity.edu.bd).

K. M. A. Al Woadud is a Lecturer in the Department of Electrical and Electronic Engineering (EEE), Uttara University (UU), Dhaka-1230, Bangladesh. (e-mail: woadudru50@gmail.com). very good performance and expected outcome. PV panel actually works to manage DC current that actually converted to AC through inverter, although the main concentration is clean the environment as much as possible [12]-[16]. To do so, TRX is highly needed to make the system proper handed. Where the PV panel is used as for DC signal achieving, but other side of the system is connected to grid that used for AC signal. The use of photovoltaic panel for power generation is becoming larger in number and use due to these panels' affordable prices, hence day by day the capacity and popularity of using PV panel increases almost exponentially. It can be more empathized if the temperature and dust of PV panel is reduced. A model circuit representing a PV cell is as shown in Fig. 1, where I is overall current, $I_{P H}$ is the photo-generated current, $R_{S}$ is panel series resistance and $\mathrm{R}_{\mathrm{SH}}$ is the panel parallel (shunt) resistance [9],[17]-[24].

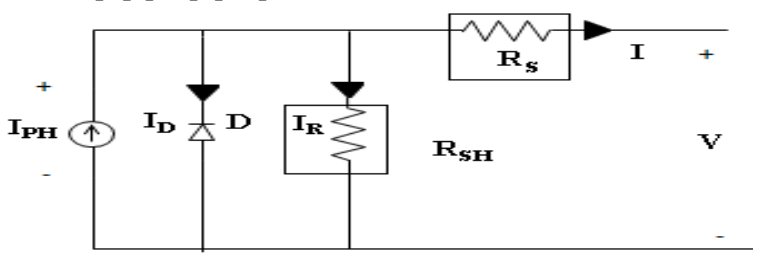

Fig. 1. Photovoltaic (PV) Cell equivalent circuit [9]

In photovoltaic panels the output depends on temperatures, load conditions as well as various irradiance which are very important for maximum power point tracking (MPPT) that can be found by I-V characteristics and V-P curves. Meanwhile, in above circuit diagram, maximum power depends on output achieving voltage and current where the output current is exponentially developed with junction thermal voltage $V_{t}$, that shown through below equation.

$$
I=I_{P H}-I_{0}\left(e^{\frac{V+I_{R}}{n_{s} V_{t}}}-1\right)-\frac{V+I_{R_{S}}}{R_{S H}}
$$

and where

$$
V_{t}=\frac{A_{K T} T_{\text {stc }}}{q}
$$

Where

$$
\begin{aligned}
& \mathrm{A}=\text { diode quality factor (ideally), } \\
& \mathrm{K}=\text { Boltzmann's constant, } \\
& \mathrm{q}=\text { The charge of the electron, } \\
& \mathrm{n}_{\mathrm{s}}=\text { The number of cells, } \mathrm{T}_{\mathrm{stc}}=\text { standard test constant } \\
& \text { (stc) temperature in Kelvin. } \\
& \mathrm{I}_{0}=\text { dark saturation current in STC. }
\end{aligned}
$$

Such model study is useful in understanding the nonlinear behavioral performance of PV cells which could be 
useful in extracting maximum power from the photovoltaic arrays. In addition, Grid connected inverter is nowadays highly popular to get high range of power point over the system where the maximum points are developed through analog maximum or normal point tracking methods [1]-[3]. Previously isolation TRX-based topology had highly populated, although the main predicament is size, cost and efficiency. In contrast, to recover these problems, the best solution would be used no TRX-based topology for both cases single phase and three phase [5]-[6]. As for getting tiny weight, low cost and high efficiency system no TRX topology is the best solution where the galvanic isolation is not included, the main problem can be seen that is common mode leakage issue which is actually the reason of reducing the efficiency and increasing the loss [8]-[11],[14].

Bangladesh is the prime affected country of present global warming and climate change. With many other reason of global warming one of the main reason is power generating. Normally we generate power through conventional energy like fossil fuel, coal, gas etc. It will finish within short time if we use it in this manner as present times. Also this is not eventually environment friendly energy production source. So this is the time to think for environment friendly renewable energy production source for Bangladesh. And PV TRX inverter topology is one of the environment friendly and cost effective sources for power energy. In PV applications the possibility of eradicate the TRX with inverter to decrease cost, size and losses and also increases the safety and efficiency. Some version of TRX inverter can accomplish a pack efficiency of $97.8 \%$ [24]. There are three technologies of inverter topologies:

a) low frequency,

b) high frequency,

c) TRX

In Europe market TRX inverters demand is $80 \%$, in Japan it is $50 \%$, but for the national standards USA TRX converter is not working there, in Bangladesh market demand for TRX inverter increases day by day especially in rural area [25].

In the next steps will be discussed about the different types of Transformer-based and TRX inverter topologies. After that, analysis the cost of TRX inverter topology to grid connection and different marking processes of PV-TRX Inverter topology to grid connection. At the end, the comparison has shown with Bangladesh.

\section{DifFERENT TOPOLOGIES}

In the case of applications just for the lighting load of a single house, the voltage obtained from solar source is boosted up through the use of a TRX. The primary of TRX is supplied by a current that is made to reverse by the switching ON and OFF in a complementary manner of a pair of transistor switches, drawing current from the line during both halves of the cycle. Once available on the secondary side, the current is rectified with a voltage more stabilized and larger than what it was on the solar source side. The limitation of the use of this kind of boosting includes besides the size and weight of the TRX used, the risk of the two transistors which may lead to shortening out the power supply (Fig. 2). As here use DC-DC boost converter for stepping the DC voltage, so the TRX used should of high frequency pulses and full bridge rectifier uses to rectify the input achieving AC signal.

DC-DC converters with coupled inductor make up another option being used in the case when extremely low input voltages need be boosted up to a usable level. The bidirectional DC-DC converter becomes highly popular due to its transferring power capability in both directions from two DC sources, but it also provides for a backup power supply power from the battery, for instance Uninterrupted Power Supplies (UPS).

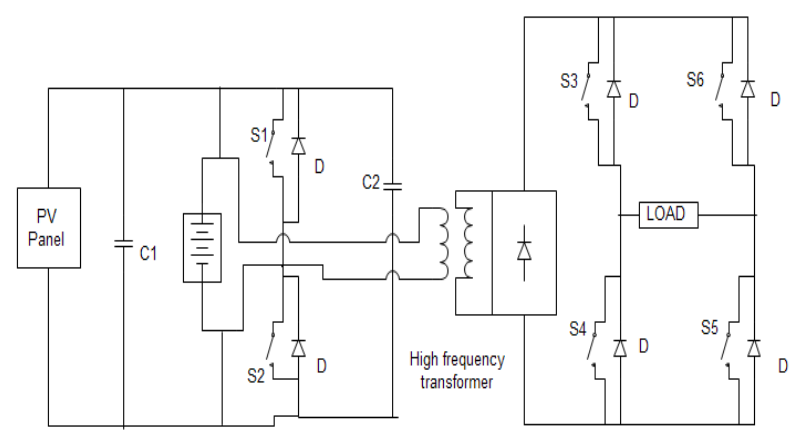

Fig. 2. DC-DC converter with High frequency TRX.

Meanwhile, TRX-based topology is commonly used in bidirectional converters as well as soft-switching techniques such as zero-current switching (ZCS) or zero-voltage switching (ZVS), but when a system uses more than four switches and diodes, the Transformer -based scheme increases the system cost and reduces the power efficiency as well. In paper (Fig. 3), are shown four power switches with coupled inductor with appropriate step up and step down ratio. Here is obtained high power efficiency both in the buck and boost mode cases. Here the using two inductances are $\mathrm{L}_{\mathrm{P}}$ and $\mathrm{L}_{\mathrm{S}}$ and winding turn $\mathrm{N}$ also depends on these inductances:

$$
N=\sqrt{\frac{\mathrm{L}_{\mathrm{S}}}{\mathrm{L}_{\mathrm{P}}}}
$$

On the other hand, equivalent magnetizing inductor, LMS is the largest than the value of $L_{S}$ or $L_{P}$ and hence, possible to reduce the ripple factor, moreover, the equivalent magnetizing inductor depends on inductances and winding turn, and the equation is:

$$
\operatorname{LMS}\left(1+\frac{1}{\mathrm{~N}}\right)^{2} \mathrm{~L}_{\mathrm{S}}=(1+\mathrm{N})^{2} \mathrm{~L}_{\mathrm{P}}
$$

In contrast, paper also shown the duty ration responds voltage gain which is 1 to 4 turn ration $(\mathrm{N})$, conventional power efficiency with output power can be seen here for bidirectional converter where the maximum achieving power efficiency is around $26.5 \%$ and $25 \%$ for boost and buck mode accordingly. 


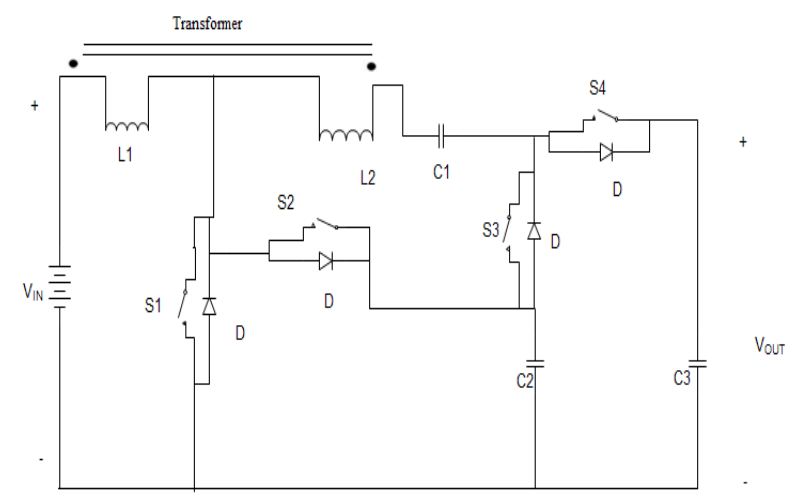

Fig.3. Bidirectional Converter.

Distributed generation is becoming commonly used technique for harvesting electric power from solar, to be installed very soon in most of the new township schemes. In this case the solar needs be stabilized before it is converted into a proper AC for connectivity to supply from main grid. For proper connectivity, the voltage waveform on the grid is being checked constantly by a DSP-based controller which is going to control switches such that the voltage gets connected at proper time and at a perfect zero crossing. Such kind of DG are also termed as micro generation as shown in Fig. 4.

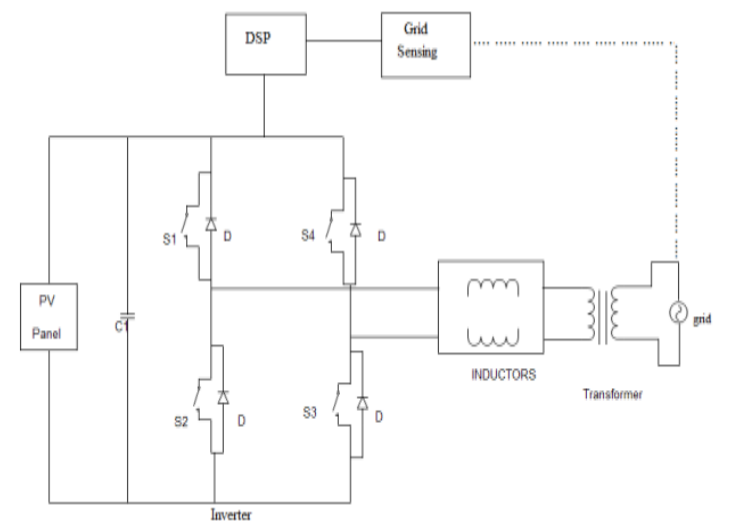

Fig. 4. Transformer-Based Inverter.

TRX photovoltaic panel is well known for high efficiency and low size and cost. However, it gives rise to the possibility of current flow between inverter and ground that actually is reason of power losses and that of the Electromagnetic Interference (EMI), current harmonics and as well as safety concerns. In order to enhance the efficiency in (Fig. 5) is proposed a new topology where they used.

MOSFETs as a switches in H5, H6 and Dual-paralleledbuck inverters configurations [26]. There are six switches used with three diodes in their proposed technique showing the function of the circuit diagram in active and freewheeling stage during the positive and negative half cycles. As we know that efficiency is partly affected by the leakage current, hence power losses are shown in the case of proposed topology in H5, H6 and Double Paralleled Buck inverter configurations for $20 \mathrm{kHz}$ frequency. The power efficiency achieved stands at around $99.3 \%$ and $98.8 \%$ for $20 \mathrm{kHz}$ and $40 \mathrm{kHz}$ switching frequencies respectively. The H5 configuration is shown in Fig. 5 where five switches have presented and in between these five switches is used a switch S5 for enabling DC passed onto inverter whereas rest of the switches are used for inverter control purposes.

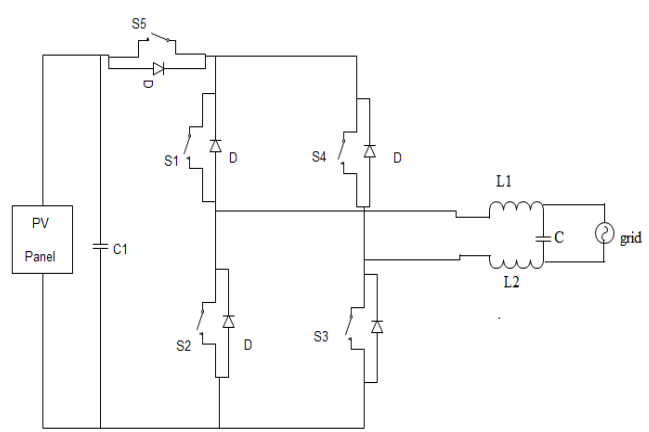

Fig. 5. H5 type topology.

Both H5 and HERIC are very high range of power efficiency-based cost-effective converters. In paper (Fig. 6) is proposed the same topology with additional improvement by adding two step-down converters compared to those of a single-phase TRX inverters. The switches are low frequency, and so it is easy to obtain a higher efficiency as well as reliability as the number of semiconductor devices is reduced with simple configuration to implement. Moreover, here are shown the different circuits for analyzing the single phase TRX PV inverter topologies for high efficiency such as Karschny, Heric extended input-voltage in H5 topology by connecting Free-wheeling diodes for combating the phenomenon of fly-back spikes generation, and the effect of duty cycle is verified. In this paper, as shown in Fig. 6, the circuit is made from four switches connected is different manner. The switches S1 and S2 are used for letting DC passed while the remaining two switches are connected with a filter shunted with resistance $\mathrm{R}$.

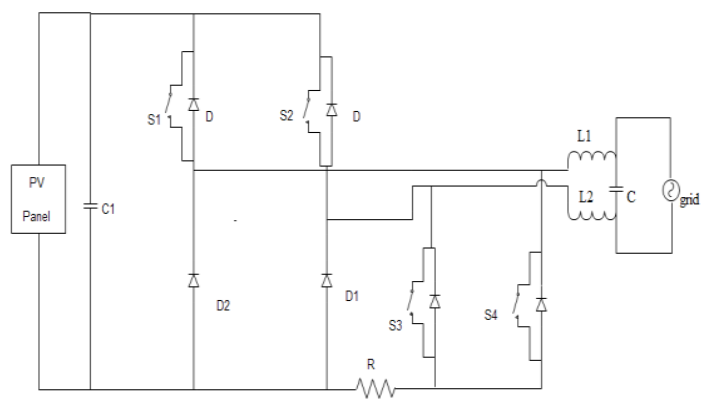

Fig. 6. Step down converter based TRX topology.

In Fig. 7 is shown the Karschny inverter topology made from five switches based topology where inductor is connected in middle of S1 and S2 switches and D1 is connected in between S5 and S1 while D2 is allied in between $\mathrm{S} 4$ and $\mathrm{S} 2$.

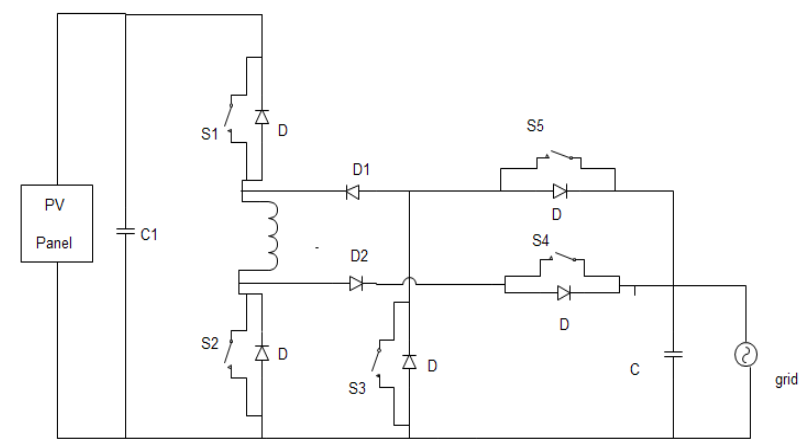

Fig. 7. Karschny inverter topology. 
In the case of low input voltage using only bridge-based inverter topology, one has to use many stages of DC-DC boost to bring it to some usable voltage level. In paper22 is discussed topology with additional components of inductances used with two switches S5 and S6 for Heric topology (Fig. 8). This is simulated and verified achieving AC signal from the inverter whereas two extra switches for Hybrid bridge topology (Fig. 9) are added with middle of the inverter having two diodes in series with the inverter.

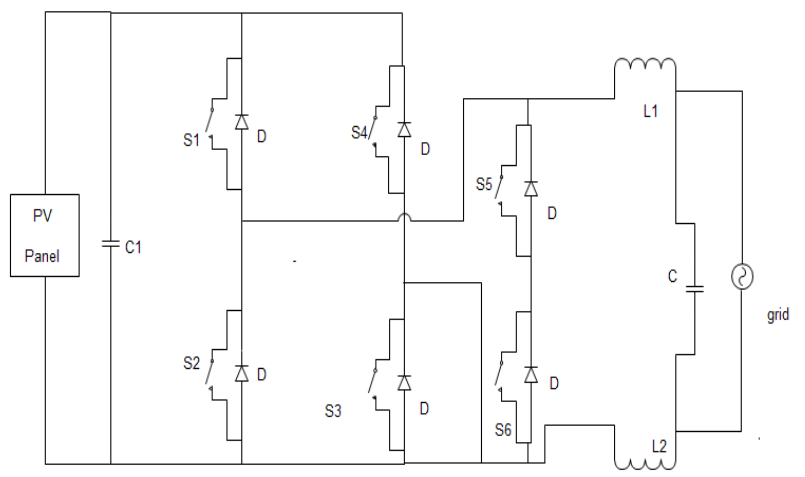

Fig. 8. HERIC type topology.

Although having the benefits of the small size, high efficiency, reliability and low cost, TRX topologies are with the limitation of common-mode voltage development which leads to having three-fold increase in leakage current than using TRX-based topology of galvanic isolation benefits. To overcome these problems in is proposed a new highly attributed buck-boost TRX topology.

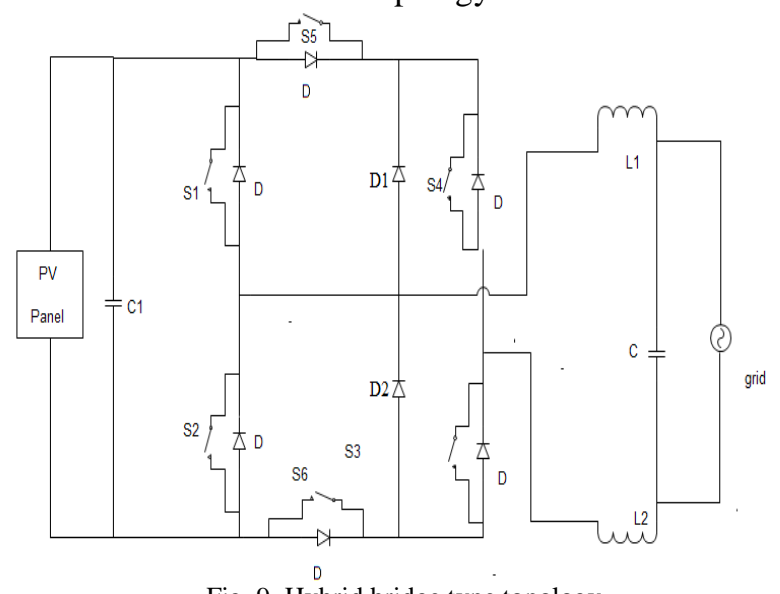

Fig. 9. Hybrid bridge type topology.

It is included with inductors coupled with the feature of stepping up or down the input voltage from PV panel. Buck and boost models with four steps are shown where is given the circuit diagram and brief discussion to explore the effect of duty cycle on its wave shapes. The experimental setup is given for verifying different wave shapes of voltage and current in buck and boost modes with different input voltages, showing thus an improved efficiency. In Fig. 10 below is shown the TRX PV inverter using buck-boost where the four switches S1, S2, S3, and S4 are connected with coupled inductor L1 and L2 and diodes D1, D2, D3, and D4 for providing electrical isolation, rest of the four switches are connected in grid format.

The normal model of the PV grid tied connected system is as simple as connection of PV panel to grid through filter and inverter and hence, its demand increases rapidly in commercial and residential structural way for every sector. On the other hand, different inverter topologies are helped to increase the power efficiency whereas the common mode voltage is developed.

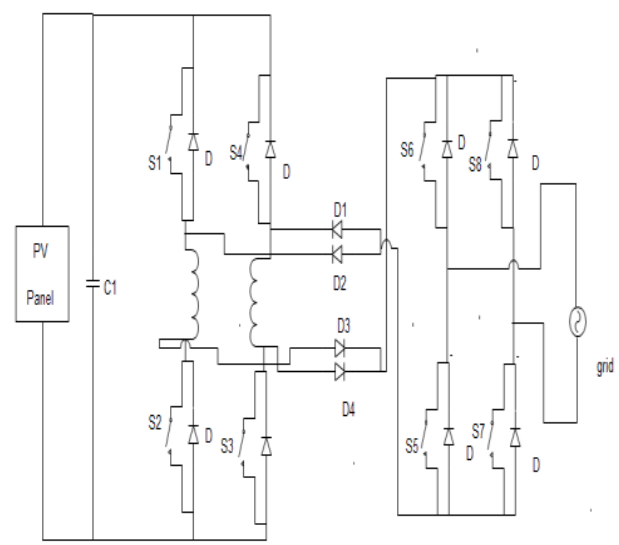

Fig. 10. TRX inverter using buck-boost.

Beside the common mode voltage development and reducing leakage current issue, some topologies perform well, in this purposes, in paper [28] it is proposed H6 topology is actually high efficient and good experimental and simulated topology to get expected outcome. H6 topology (Fig. 11) has six switches and two diodes where these two diodes are connected as a cross couple of using two extra switches in the middle of the normal inverter. All of these six switches are used to get ac signal from the inverter where the diodes are helped to get it smoothly [27].

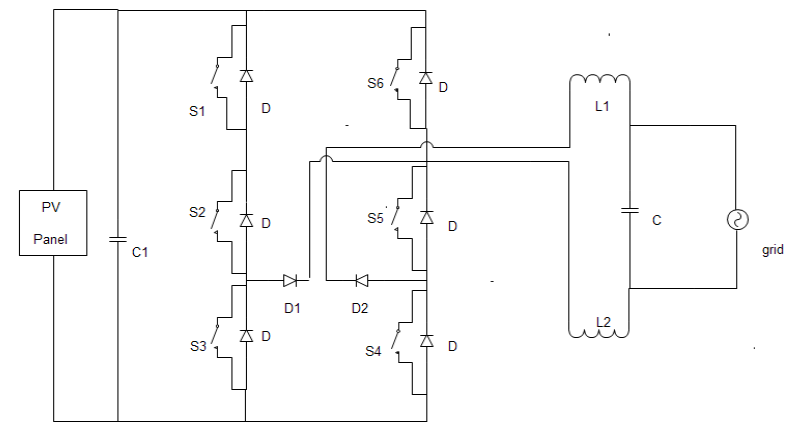

Fig. 11. H6-type topology.

\section{APPRoXimate AND Potential PER UNIT COSTING OF PV TRX INVERTER SYSTEM}

\section{A. Direct Costing}

Land, Natural resources, Detail engineering design, Equipment (solar panels, Inverter, Battery, charge controller, wiring, panel mounting etc), installation works, raw materials, and supply constriction.

\section{B. Indirect Costing}

Administrative cost, operating cost, energy and fuel, labor, Depreciation of natural resources and equipment, sunk cost, technical support, foreign exchange economical value cost [28]-[30]. 
TABLE I: APPROXIMATE COSTING FOR PV TRX SYSTEM IN BANGLADESH [29].

\begin{tabular}{lll}
\hline SL & Description of Items & TK \\
\hline 1 & Solar panel $(100 \mathrm{w}-\mathrm{h})$ & 24500 \\
\hline 2 & Battery 150 AmH & 12000 \\
\hline 3 & Charge controller & 2000 \\
\hline 4 & Wiring & 2000 \\
\hline 5 & Panel Mounting & 2000 \\
\hline 6 & Miscellaneous & 1000 \\
\hline & Total cost & 45500 \\
\hline
\end{tabular}

Though the solar isolation is better in Bangladesh but still as under developing country Bangladesh still cannot use it properly for its less technological establishment. But it is encouraging that Bangladesh is now trying to install PV TRX system in various establishments. Also it can be identified on the Fig. 12 [29].

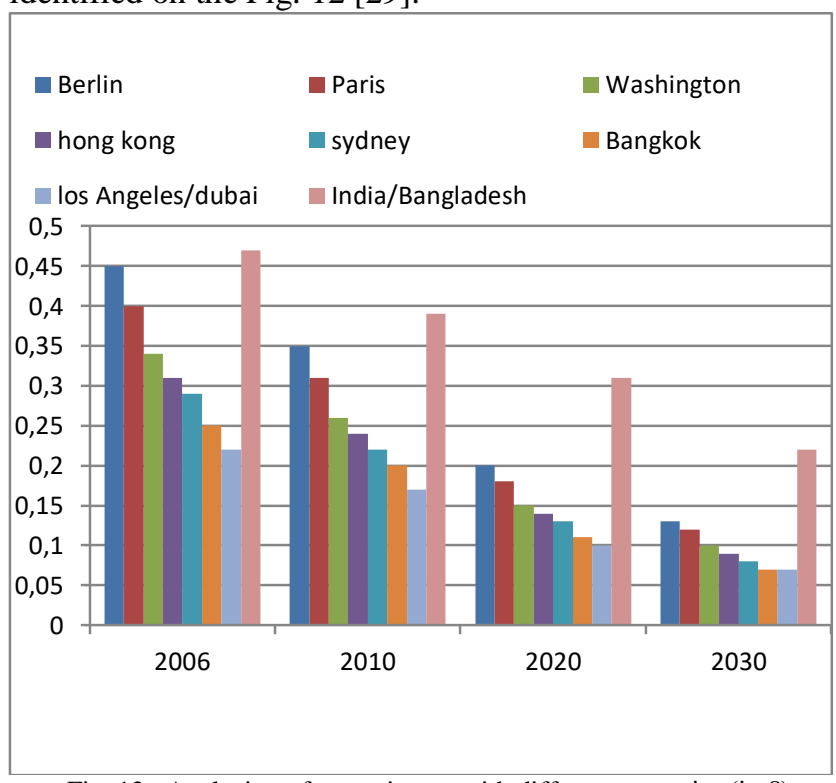

Fig. 12. Analysing of per unit cost with different countries (in $€$ ).

Cost of the PV TRX -less inverter topology decries with the comparison of other sources of energy in the country (Fig.13) [25],[29].

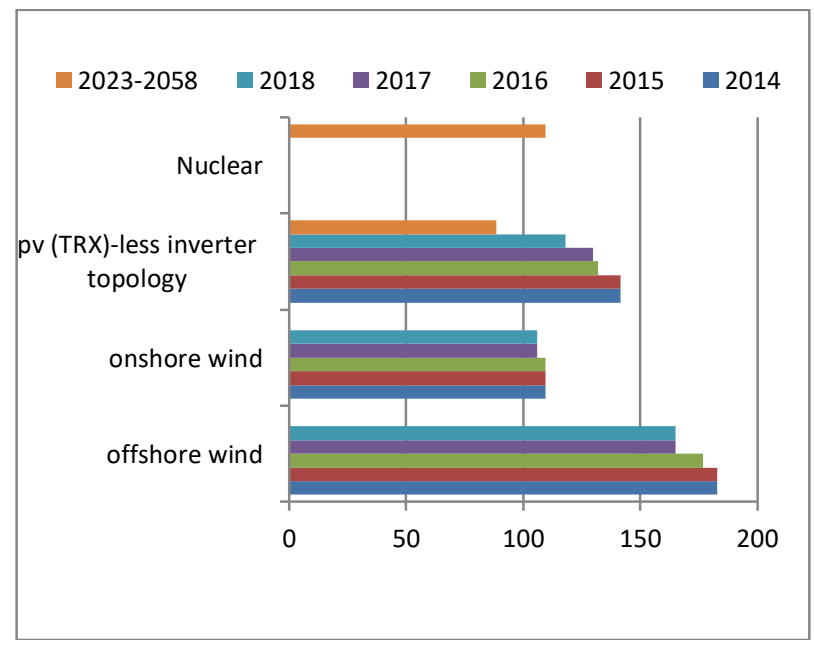

Fig: 13. Cost analysis of different source of natural energy sources (in $€$ ) [29].

Fig. 14 shows some proposed topology technology for Bangladeshi energy grids and its installation costs in Europe. It give us the idea of costing to develop Bangladeshi solar energy TRX grids [30]-[31].

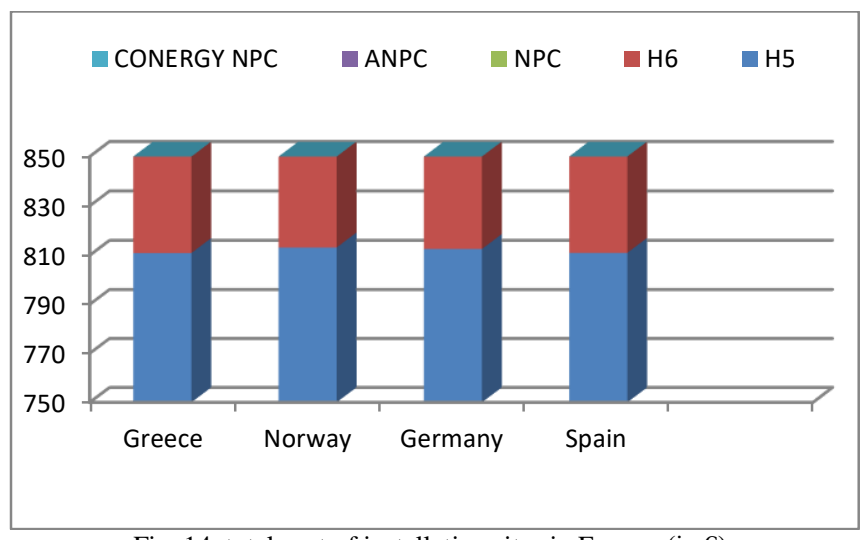

Fig. 14. total cost of installation sites in Europe (in $€$ ).

\section{MARKeting Process}

Solar energy is the most readily available and free source of energy in our country and traditionally solar thermal energy has been utilized in different household and industrial activities in Bangladesh. Several organizations have installed low capacity wind turbines, mainly for battery charging in the coastal region of Bangladesh. However, progress in the wind energy sector of Bangladesh is not impressive. In that case Bangladesh is very potential market for PV TRX inverter use in homes as well in commercial places.

The way of market the system:

1. Make PV TRX inverter topology Affordable

2. Make this system Patriotic

3. Make it ordinary to all level of consumer and customer

4. Make the system simple to untestable

5. Make it easy to excess to make use pleasurable

6. Make this system safer and more secured

7. Make the system user friendly

8. Make this system available to all level of consumer.

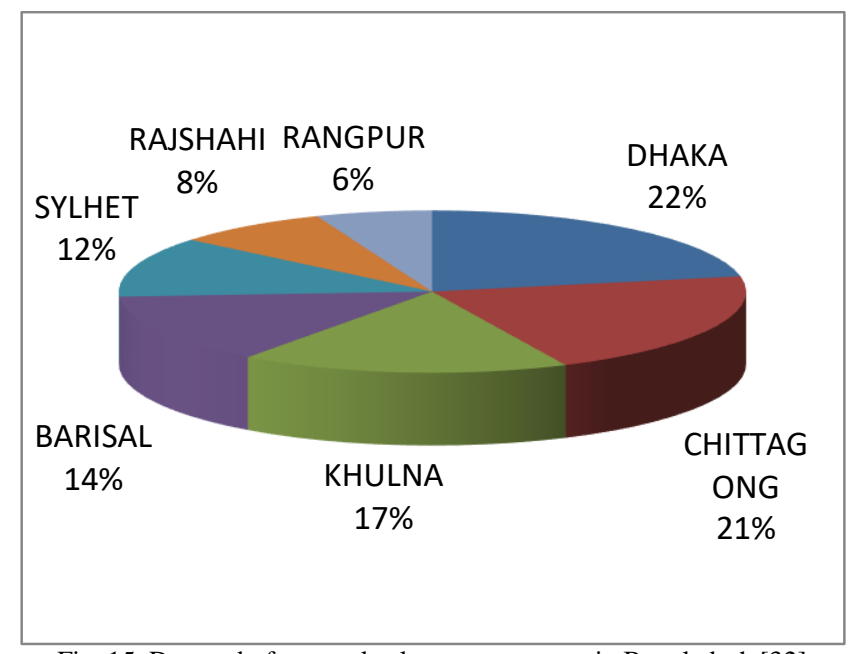

Fig. 15. Demand of renewal solar energy power in Bangladesh [32]

To make it marketable power grid organization and government can use some strategies: 


\section{A. Pull Strategy}

a. Recently government enforce to established a PV TRX or with TRX conversion grid for every establishment

b. For the insufficient electricity supply people are now demanding for solar power system.

c. Increasing cost of electricity and fuel people get the PV system less costly for long run.

\section{B. Push Strategy}

a. Government can give benefits to the people who are interested to established PV establishments.

b. As solar power is renewal energy government and authority can educate people about its betterment.

c. For its safety, cost reduction feature and size now people are interested for this system.

d. As electricity infrastructure is not well developed that's why people of rural area are now more interested about Photovoltaic Inverter system.

e. Company can provide EMI system for the system and installment.

\section{Green Economic}

Now a day's green Economic is a vital issue in manufacturing and corporate culture. Photovoltaic Inverter works as a part of green economic factor. As this system is natural and renewal as it does not create any toxic affect towards society it is now popular for its green economical factor. People need to make educate about environmental destruction effects and the usefulness of use renewal energy sources.

\section{CONCLUSION}

The cost is the vital part to setup the overall TRX inverter with grid connection where some limitation has been observed. In this paper main focusing part is cost analysis of this system and the process of marketing. Before that, here discuss more and more about the TRX based and TRX inverter topologies. Moreover, the switching functions and working principles has been discussed in this paper. Further has done the comparison of the costing and marketing process of the overall TRX inverter with grid connection with Bangladesh.

\section{REFERENCES}

[1] M. N. H. e. a. Khan, "Evaluation of Various Leakage Current Paths with Different Switching Conditions," In Computer and Communication Engineering (ICCCE), International confarence on IEEE, pp. 269-272, 2014

[2] H. Khan, Noman, M. et al., "Wave shaping with reduced leakage current in TRX inverter," In Smart Instrumentation, Measurement and Applications (ICSIMA), 2013 IEEE International Conference, pp. 1$5,2013$.

[3] H. Khan, Noman, M. et al., "DC-AC inverter with perspective of common mode and wave-shaping," In Smart Instrumentation, Measurement and Applications (ICSIMA), 2013 IEEE International Conference, pp. 1-5, 2013.

[4] M. N. H. e. a. Khan, "Leakage Current Paths in PV TRX Single-Phase Inverter Topology and Its Mitigation through PWM for Switching," International Journal of Power Electronics and Drive Systems, vol. 6, pp. 148-159, 2015.

[5] Md. Noman Habib Khan, S. Khan, T. S. Gunawan, R. I. Boby. “A Double PWM Source Inverter Technique with Reduced Leakage Currentfor Application on Standalone Systems." World Academy of Science, Engineering and Technology Electronics and Communication Engineering, Vol.9, no.2, pp. 1602-1607, 2015.
[6] M. N. H. Khan, K. J. Ahmad, M. S. Zahan, M. N. Hasan. "BatteryEquivalent DC Supply from Leakage Current: PV to TRX Inverter topology." International Journal of Electrical Engineering and Informatics (IJPEDS), Vol.7, no. 4, 2016.

[7] M. G. Rabbani, C. T. Sattary, M. R. A. Mamun, M. M. Rahman, M. N. H. Khan. "Performance Analysis of Non-Renewable Energy In Bangladesh." Indonesian Journal of Electrical Engineering and Computer Science (IJEECS). Vol. 5, No. 2, 2017.

[8] J. Leuchter, Zaplatilek, K., \& Bauer, P. , "Photovoltaic model for circuit simulation," 38th Annual Conference on IEEE Industrial Electronics Society on IEEE, pp. 5399-5405, 2012, October.

[9] D. Sera, Teodorescu, R., \& Rodriguez, P., "PV panel model based on datasheet values," In Industrial Electronics,IEEE International Symposium on IEEE, pp. 2392-2396, 2007, June.

[10] M. N. H. Khan, M.H. Delwar, Md. A. Kabir, M.S. Zahan, K. J. Ahmad, M. M. Alam \& M. T. Anower "Proposed PV TRX Inverter Topology Technique for Leakage Current Reduction." International Journal of Power Electronics and Drive System (IJPEDS), Vol. 7, No 3, pp. 929-937. 2016.

[11] B. Yang, Li, W., Gu, Y., Cui, W., \& He, X., " Improved transformerless inverter with common-mode leakage current elimination for a photovoltaic grid-connected power system," Power Electronics, IEEE Transactions on, vol. 27, pp. 752-762, 2012.

[12] Md. N. H. Khan, Md. T. Anower, Md. D. Hossen, Md. M. Alam, K. J. Ahmad."PV-TRX Inverter Topology for Battery-Equivalent DC Supply From Leakage Current." International Journal of Electrical and Computer Engineering (IJECE).Vol.6, no.5, pp. 2025-2032. October 2016.

[13] M. N. H. Khan, M. R. Hasan, M. K. Alam. "Switching Algorithm for Leakage Current Reduction in a PV- No TRX Inverter System." Indonesian Journal of Electrical Engineering and Computer Science. Vol. 4. No. 1,pp. $52-56,2016$

[14] N. H. Khan. "Performance Analysis of Common Issues In the PV TRX Inverter Topology.” European Journal of Engineering Research and Science (EJERS). Vol. 1, No. 1, pp. 43-49, 2016.

[15] M. N. H. Khan, M. T. Anower, K. J. Ahmad, M. M. Alam, M. S Zahan, Md. D. Hossen. "Photovoltaic (PV) Panel to TRX Inverter Topology: A Review Paper." Elixir Electrical Engineering Journal. Vol.93, 2016, pp. 39574-39581.

[16] M. N. H. Khan, M. M. Alam, M. T. Anowar, M. D. Hossen, K. A. Jamil and M. S. Zahan."Active and Passive Filters: Wave Shapes of Magnitude and Phase Angle". International Journal of Engineering Science and Computing. Vol.6, No.4, March 2016, pp. 3267-3271.

[17] M. N. H. Khan, M. T. Anowar, M. D. Hossen, K. A. Jamil, M. S Zahan and M. M. Alam" Effect of Leakage Current In The PV TRX Inverter Topology".International Journal of Engineering Science and Computing. Vol.6, No.4 March 2016, pp. 3272-3275.

[18] G. e. a. Gerardo, "High Efficiency Single-Phase Transformer-less Inverter for Photovoltaic Applications," Ingeniería, Investigación y Tecnología, vol. 16, pp. 173-184, 2015.

[19] M. N. H. Khan., M. R. Islam, M. S. Jamal, M. A. Hossen, M. R. Mahmud, "X-Rated Capacitor Based TRX Topology for Power Supply." International Journal Of Multidisciplinary Research And Information.Vol.2, No.9, pp. 433-437, 2016.

[20] Khan, Md, Noman Habib, Nassereldeen Ahmed Kabbashi. "Reducing corruption and developing public services in Bangladesh through EGovernment." 3rd International Conference on Engineering Professional Ethics and Education (ICEPEE'13), 2013.

[21] Khan, Md, Noman Habib, Nassereldeen Ahmed Kabbashi. "Profession of engineering ethics at work: melamine issue as case study." 3rd International Conference on Engineering Professional Ethics and Education (ICEPEE'13), 2013.

[22] Alam, M.K, S.A.Latif, F. M. H. Masud, S.Hakak, M.N.H.Khan, Farhat Anwar. "Performance analysis of high speed wireless campus network using seed values and pause times in ieee802.11e." 3rd International Conference On Informatics, Electronics \& Vision, IEEE 2014.

[23] Hasan, M. R., Ibrahimy, M. I., Motakabber, S. M. A., Ferdaus, M. M., Khan, M. N. H., \& Mostafa, M. G. "Development of a web based financial application system." In IOP Conference Series: Materials Science and Engineering, IOP Publishing, Vol. 53, No. 1, Art no. 12080, 2013

[24] Hasan, M. R., Ibrahimy, M. I., Motakabber, S. M. A., Ferdaus, M. M., \&Khan, M. N. H. "Comparative data compression techniques and multi-compression results." In IOP Conference Series: Materials Science and Engineering, IOP Publishing, Vol. 53, No. 1, Art no. 12081, 2013

[25] Bruno Burger, Dirk Kranzer, fraunhofer institute for solar energy systems ise "Extreme High Efficiency PV-Power Converters" 
[26] G. Buticchi, Barater, D., Lorenzani, E., \& Franceschini, G., " Digital control of actual grid-connected converters for ground leakage current reduction in PV transformerless systems," Industrial Informatics, IEEE Transactions on, vol. 8, pp. 563-572, 2012.

[27] Sajib Chakraborty, Wahidul Hasan, S. M. Baque Billah "Electrical Engineering and Information \& Communication Technology (ICEEICT), 2014 International Conference on"

[28] Zhang, Sun, K., Xing, Y., \& Xu, M. (2013). H6 Transformerless FullBridge PV Grid-tied Inverters, "H6 Transformerless Full-Bridge PV Grid-tied Inverters," Power Electronics, IEEE Transactions on, vol. 29, pp. 1229-1238, 2013

[29] Md. Habib Ullah et al. Current Status of Renewable Energy Sector in Bangladesh and a Proposed Grid Connected Hybrid Renewable Energy System. International journal of advanced renewable energy research. Vol. 1, No. 11, pp. 618-627, 2012

[30] Saridakis, optimal design of modern TRXless PV inverter topology. IEEE transactions on energy conversion, vol. 28, No.2, pp. 394-404, 2013.

[31] Youguang Guo Affiliated with School of Electrical, Mechanical and Mechatronic Systems, Faculty of Engineering and Information Technology, University of Technology Sydney (UTS), Jianguo Zhu "Power Converters for Small- to Large-Scale Photovoltaic Power Plants'

[32] Mst. Juthika Azad. Estimation and analysis of Rooftop Solar PV Power system in Bangladesh. Institute of Energy, University of Dhaka. MS Thesis in Renewable Energy Technology (RET). 2016

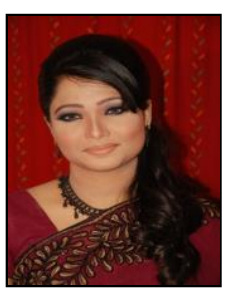

Shahreen noor was born in Bangladesh on 1988. She completed her Bachelor in Business Administration from East West University. Her major area of BBA was on Human Resource Management and Finance. Also she completed her Masters on Business Administration from East West University. Her major was on Human Resource Management and minor on Marketing. She started working at Uttara University from 2014. Her interest to work on motivational factors affected on human resource.

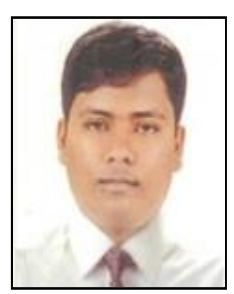

Md. Noman Habib Khan received the B.Sc degree in Electrical and Electronic Engineering (EEE) from Ahsanullah University Science and Technology (AUST), Bangladesh in 2009. However, he already finished his M.Sc degree from International Islamic University Malaysia (IIUM), Malaysia at 2014 and had been doing work as a research assistant at UMPEDAC department at University of Malaya (UM) with renewable energy especially solar, hydro, wind and hybrid for electrification issue. Now at present, he is doing work as a Lecturer in the Department of Electrical and Electronic Engineering (EEE), Uttara University (UU), Dhaka, Bangladesh

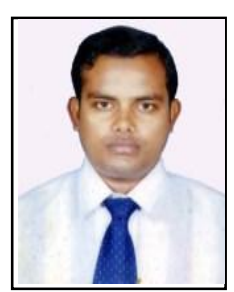

K.M. Abdul Al Woadud was born in Bangladesh on 1986. He completed his Bachelor in Mathematics from the University of Rajshahi at 2009. And also he completed his Masters on Mathematics from the University of Rajshahi at 2010. He started working at Uttara University from 2013 .. 